\title{
The contribution of patients' lung function to the inspiratory airflow rate achievable through a DPIs' simulator reproducing different intrinsic resistance rates
}

\author{
Roberto W. Dal Negro, ${ }^{1}$ PaolaTurco, ${ }^{2}$ Massimiliano Povero ${ }^{3}$ \\ ${ }^{1}$ National Centre for Respiratory Pharmacoeconomics and Pharmacoepidemiology, Verona \\ ${ }^{2}$ Research \& Clinical Governance, Verona, Italy \\ ${ }^{3}$ AdRes Health Economics and Outcome Research, Turin, Italy
}

Background: The performance of DPIs depends on several physiological (patient-dependent) and technological (device-dependent) factors. The inspiratory airflow rate is the only active force generated and operating in the system for inducing the required pressure drop and eliciting the resistance-induced turbulence needed to disaggregate the powder through the device. The present study aimed to investigate in the most prevalent respiratory disorders whether and at what extent the inspiratory airflow rate achievable when inhaling through a DPIs' simulator reproducing different intrinsic resistance regimens (low, mid, and high resistance) is affected by peculiar changes in lung function and/or can be predicted by any specific lung function parameter.

Methods: The inspiratory airflow rate was assessed in randomized order by the In-Check DIAL G16 at low, mid, and high resistance regimens in a sample of consecutive subjects at recruitment. Independent predictors of the probability to achieve the expected inhalation airflow rate were investigated by means of a multivariate logistic regression model, specific to the disease.

Results: A total of 114 subjects were recruited (asthmatics $n=30$; COPD $n=50$, restrictive patients $n=16$, and normal subjects $n=18$ ). The mean values of the expected inspiratory airflow rate achieved proved significantly different within the groups $(\mathrm{p}<0.0001)$, independently of sex and age. In asthmatics and in COPD patients, the mid-resistance regimen proved highly associated with the highest mean values of airflow rates obtained. Low- and high-resistance regimens were significantly less likely to consent to achieve the expected level of inspiratory airflow rate $(\mathrm{OR}<1$ in all comparisons). Restrictive patients performed the lowest airflow rates at the low-resistance regimen (p<0.01). Unlike FEV ${ }_{1}$, $\mathrm{RV}$ in asthmatics $(\mathrm{OR}=1.008) ; \mathrm{RV}$ and $\mathrm{I}_{\mathrm{Raw}}$ in $\mathrm{COPD}(\mathrm{OR}=0.587$ and $\mathrm{OR}=0.901$, respectively), and FIF and TLC in restrictive patients $(\mathrm{OR}=1.041$, and $\mathrm{OR}=0.962$, respectively) proved the only sensitive predictors of the inspiratory airflow rate achievable at the different resistive regimens.

Conclusions: The intrinsic resistive regimen of DPIs can play a critical role. The patients' lung function profile also affects the extent of their inhalation airflow rate. Some specific lung function parameters (such as: FIF; RV; $\mathrm{I}_{\mathrm{Raw}}$; TLC, but not $\mathrm{FEV}_{1}$ ) may be regarded as specific predictors in real-life. In order to optimize the DPI choice, further to the device's technology, also the current patients' lung function should be properly investigated and carefully assessed.

Key words: DPIs; inspiratory airflow; intrinsic resistance; lung function; predictors; obstructive and restrictive patients; normal subjects.

Correspondence: Massimiliano Povero, AdRes Health Economics and Outcome Resources, Via Vittorio Alfieri 17, 10121 Torino, Italy. E-mail: m.povero@adreshe.com

Contributions: All Authors contributed equally to the study, read and approved the final manuscript.

Conflict of interest: The authors declare the absence of any conflict of interest. RWD is Associate Editor of Multidisciplinary Respiratory Medicine.

Availability of data and materials: Authors do not wish to share their data without their permission.

Ethics approval and consent to participate: The study was approved by the Ethical and Scientific Commission of the National Centre for Respiratory Pharmacoeconomics and Pharmacoepidemiology during the session of June $10^{\text {th }}, 2020$. All subjects gave their informed consent to the anonymous use of their own data for research purposes.

Consent for publication: All subjects gave their informed consent. 


\section{Introduction}

Drugs delivered by inhalation are particularly suitable and convenient in respiratory medicine because they target the lungs directly, consent a lower dose together to a quick onset of action, thus leading to a better therapeutic index $[1,2]$.

Despite the great progress in delivery technology mainly aimed to facilitating the inhalation procedures and optimizing the therapeutic outcomes of prescribed drugs, the real-life effectiveness of all inhaled medications still represents a major challenge in the management of respiratory patients, since it can be variably affected by several physiological (patient-dependent) and technological (device-dependent) factors [3,4-6]. At present, out of the three major classes of pocket portable devices (Metered Dose Inhalers - MDIs; Dry Powder Inhalers - DPIs; Soft Mist Inhalers SMIs), DPIs are the most used for regular treatments even if they require a stronger and deeper effort for drug inhalation when compared to MDIs and SMIs, and have variable usability scores [7-8].

DPIs can be grouped in three main families by their intrinsic resistance, such as the peculiar constant due to their original engineering which is measurable by assessing the pressure drop across the device itself [9]. The inspiratory airflow rate is the only active force operating in the system for inducing the required pressure drop and eliciting the resistance-induced turbulence needed to disaggregate the powder trough the device. It is then presumable that any subjects' respiratory limitation related to their current lung disorder may variably contribute to affect the expected airflow rate across the DPIs.

The aim of the present study was to investigate (in the most prevalent respiratory disorders) whether or not the inspiratory airflow rate achievable when inhaling through a DPIs' simulator reproducing different intrinsic resistance regimens, is affected by peculiar changes in lung function and/or can be predicted by any specific lung function parameter.

\section{Methods}

A sample of consecutive Caucasian individuals with normal cognition and normal handling ability, referring to the Lung Unit of the CEMS Specialistic Center (Verona, Italy), was recruited in the period June 15 - September 30, 2020. Obstructive patients were numerically privileged because those who mostly need the proper delivery of inhaled drugs for controlling effectively their airway flow limitation, while restrictive patients and normal individuals were also included in order to provide extreme reference ranges in terms of lung volumes and flows.

Age, sex, body mass index (BMI), and several lung function parameters were assessed (Plethysmography Platinum DX Elite, MedGraphics, Saint Paul, MN, USA) in all subjects at recruitment: forced expiratory volume in 1 second $\left(\mathrm{FEV}_{1}\right)$, inspiratory capacity (IC), forced inspiratory volume (FIV), forced inspiratory flow (FIF), total lung capacity (TLC), maximal expiratory flow at $25 \%$ $\left(\mathrm{MEF}_{25}\right)$ of lung filling, residual volume $(\mathrm{RV})$, inspiratory and expiratory resistance $\left(\mathrm{I}_{\text {Raw }}\right.$ and $\mathrm{E}_{\text {Raw }}$, respectively). $\mathrm{FEV}_{1}, \mathrm{IC}, \mathrm{TLC}$, and RV were expressed both in $\mathrm{L}$ and \% predicted; FIV, $\mathrm{I}_{\text {Raw }}$ and $\mathrm{E}_{\text {Raw }}$ in L; FIF and $\mathrm{MEF}_{25}$ both in $\mathrm{L} / \mathrm{sec}$ and \% predicted.

The In-Check DIAL G16 (Clement Clarke Int. Ltd., Harlow, UK), such as a specialized inspiratory peak flow meter (measurement range of $15-1201 / \mathrm{min}$ ) was used as it allows to perform an inspiratory flow effort consistent with the requirements of several specific inhaler devices [10]. As the In-Check DIAL G16 is a DPIs simulator reproducing the resistance profile of several DPIs, it was used to check the patients' forced inspiratory airflow rate at low, mid, and high resistance regimens [9-11].

As it was defined that for a given maximum inspiratory pressure drop of $4 \mathrm{kPa}$ across the device, the low-resistance regimen is characterized by an inspiratory flow resistance $<0.02 \mathrm{kPa}^{0.5} \mathrm{~min} / 1$ and requires a flow rate $>100 \mathrm{l} / \mathrm{min}$; while the mid-resistance regimen by inspiratory flow resistance values ranging $0.020-0.040$ $\mathrm{kPa}^{0.5} \mathrm{~min} / \mathrm{L}$ and requires flow rates ranging 100-50 1/min, and the high-resistance regimen by inspiratory flow resistance values $>0.040 \mathrm{kPa}^{0.5} \mathrm{~min} / 1$ and requires flow rates $<501 / \mathrm{min}[3,9,12-17]$, the inspiratory flow rates assessed by means of the In-Check DIAL G16 were therefore compared to these expected reference values.

All subjects had been preliminary educated to the proper use of the In-Check DIAL G16 by expert technicians. Each subject was tested at the same low, mid, and high resistance regimen in random order at recruitment, and only the best inspiratory airflow rate out of three sequential and comparable attempts (inter-measure variability $\leq 5 \%$ ) was considered for calculations and comparisons. Moreover, the number of individuals who achieved the inspiratory airflow limits expected for each resistance regimen [3,9,12-17] was also counted in each group of subjects. At recruitment, all subjects gave their informed consent to the anonymous use of their own data for research purposes. The study was approved by the Ethical and Scientific Commission of the National Centre for Respiratory Pharmacoeconomics and Pharmacoepidemiology during the session of June $10^{\text {th }}, 2020$.

\section{Statistics}

Sample size was calculated according to the formula proposed by Concato and Peduzzi [18] for logistic regression models ( $\mathrm{N}=10$ $\mathrm{x} \mathrm{k} / \mathrm{p}$ ) assuming $\mathrm{p}=30 \%$ of patients achieving optimal inhalation airflow rate and $\mathrm{k}=3$ covariates included in the multivariate model. The proportion $\mathrm{p}$ was estimated analyzing patients enrolled in the first month of the study whereas the number of covariates was assumed small (3) because, according to previous literature, the number of parameters affecting the inspiratory flow rate is low $[3,19,20]$. According to our assumptions, 100 patients were considered adequate for this study.

Continuous data were presented as means and standard deviation (SD), while categorical data as absolute and relative frequencies. Differences in baseline characteristics and lung function among the groups recruited were tested by ANOVA, and the Tukey correction was applied when specific intra-group comparisons were tested.

The association between the probability to achieve the expected airflow rates (see methods) when inspiring through the three resistance regimens tested and each lung function parameter assessed was checked by a series of univariate logistic models. This association was measured in terms of odds ratio (OR): an OR $>1$ indicates a positive association with the tested variable (i.e., the probability to be effective increases as the variable increases), while an OR $<1$ indicates a negative association with the tested variable (i.e., the probability to be effective decreases as the variable increases). Due to the heterogeneity of the groups recruited (such as, normal controls; asthmatic, COPD, and restricted patients), the regression models were run separately for each population. Furthermore, all variables that resulted associated with the outcome (defined as $\mathrm{p}<0.20$ ) were included in a multivariate logistic model, and the best set of predictors was automatically extracted by using a stepwise (backward) selection algorithm.

All statistical calculations were carried out by means of STATA (StataCorp. 2017. Stata Statistical Software: Release 15; StataCorp LLC, College Station, TX, USA). 


\section{Results}

A total of 114 consecutive Caucasian individuals were tested: 80 obstructive patients ( 30 asthmatic and 50 COPD), 16 restrictive patients, and 18 normal controls. The characteristics of the whole sample and of each group of individuals are reported in Table 1. Subjects were evenly distributed in terms of sex and BMI. As expected, normal subjects and asthmatics were younger than COPD and restrictive patients ( $<<0.05$ after Tukey correction). The lung function profile assessed proved physiologically corresponding to the original lung disease or condition in each group of subjects (Table 1).

In general, the subjects' mean airflow rate decreased almost linearly by increasing the resistance regimen in all groups (nonparametric test for trend, $\mathrm{p}<0.001$ ) (Figure 1 ). The inspiratory airflow proved highly different $(\mathrm{p}<0.0001)$ in normal subjects, $v s$ asthmatic, vs COPD, and $v s$ restrictive patients (Figure 1). The majority of pairwise comparisons between groups showed highly different responses with both the mid- and the high-resistance regimens $(p<0.023$ and $p<0.008$, respectively). In particular, restrictive patients performed the lowest airflow rates with the low-resistance regimen, $(p<0.01$ after Tukey correction for multiple comparisons). Only when mean airflow rates of asthmatic patients were compared to those of normal controls, and when mean airflow rates of asthmatic (for mid- and high-resistance regimens) and normal (for low-resistance regime) patients were compared to those of COPD patients no significant difference was observed.

Analytic results of univariate regression are listed in Supplementary Table S1. Asthmatic and COPD subjects, inspiring at low- and high-resistance regimens were significantly less likely to perform their expected inspiratory airflow rates with respect to those inspiring at mid-resistance $(\mathrm{OR}<1$ in all comparisons). Results were confirmed by the multivariate regression (Table 2). In other words, the low-resistance DPIs are less likely to consent optimal inhalation airflow rates in obstructive patients (asthma and COPD) because they would need a too high inspiratory airflow $(>100 \mathrm{l} / \mathrm{min}$ ), and this level of flow is not achievable by all subjects (Table 2). Conversely, the high resistance DPIs are less likely to consent optimal inhalation airflow rates in these patients because the resistance to overcome by inhalation is too high and their flow limitation limits the forced inspiratory maneuver. The mid-resistance DPIs prove the more balanced and then the more suitable and reliable in real-life clinical terms. Moreover, as no restrictive patient was able to achieve the expected airflow rate at low-resistance regimen, only comparisons between the airflows rates obtained at mid- and high-resistance regimens were then possible. Differently from all other groups, restrictive patients produced a better airflow rate at high-resistance regimen $(\mathrm{OR}=7.228,95 \% \mathrm{CI}$ 0.92 to 56.76 )

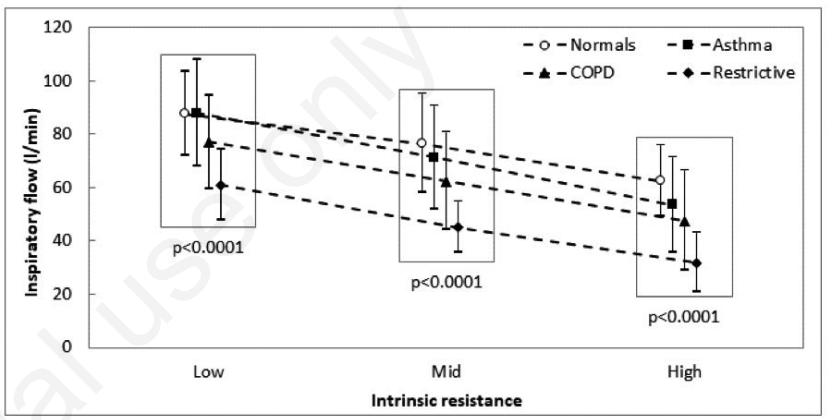

Figure 1. Trend of mean inspiratory airflow rate assessed at the three intrinsic resistance regimens (bars represent $\pm S D$ ).

Table 1. Mean \pm SD of baseline characteristics and lung function in the whole sample and in the four groups (sex was expressed as absolute and relative frequency).

\begin{tabular}{|c|c|c|c|c|c|c|}
\hline n. & $\begin{array}{l}\text { Total } \\
114\end{array}$ & $\begin{array}{c}\text { Normal } \\
18\end{array}$ & $\begin{array}{c}\text { Asthma } \\
30\end{array}$ & $\begin{array}{c}\text { COPD } \\
\mathbf{5 0}\end{array}$ & $\begin{array}{c}\text { Restrictive } \\
8\end{array}$ & $\mathbf{p}$ \\
\hline Sex (\% male) & $49(43 \%)$ & $11(61.1 \%)[\mathrm{A}]$ & $12(40 \%)[\mathrm{A}]$ & $23(46 \%)[\mathrm{A}]$ & $8(50.0 \%)[\mathrm{A}]$ & 0.5614 \\
\hline Age & $61.4 \pm 15.2$ & $56.2 \pm 10.9[\mathrm{AB}]$ & $49.7 \pm 17.2[\mathrm{~A}]$ & $69.2 \pm 10.2[\mathrm{C}]$ & $64.4 \pm 12.3[\mathrm{BC}]$ & $<0.0001$ \\
\hline BMI & $24.9 \pm 5.4$ & $25 \pm 3.6[\mathrm{~A}]$ & $25.6 \pm 6[\mathrm{~A}]$ & $25.4 \pm 5.3[\mathrm{~A}]$ & $22.3 \pm 5.4[\mathrm{~A}]$ & 0.1944 \\
\hline $\mathrm{FEV}_{1}(\mathrm{l})$ & $2.4 \pm 1$ & $3.5 \pm 0.8$ & $2.9 \pm 0.8$ & $1.8 \pm 0.6[\mathrm{~A}]$ & $2 \pm 0.7[\mathrm{~A}]$ & $<0.0001$ \\
\hline $\mathrm{FEV}_{1}(\%$ pred $)$ & $84 \pm 22.4$ & $111.3 \pm 10$ & $93.1 \pm 15.3$ & $71.1 \pm 18.8[\mathrm{~A}]$ & $76.6 \pm 18.7[\mathrm{~A}]$ & $<0.0001$ \\
\hline $\mathrm{IC}(\mathrm{l})$ & $2.5 \pm 0.8$ & $3 \pm 0.9[\mathrm{~B}]$ & $2.8 \pm 0.7[\mathrm{~B}]$ & $2.3 \pm 0.7[\mathrm{~A}]$ & $1.9 \pm 0.8[\mathrm{~A}]$ & $<0.0001$ \\
\hline IC (\% pred) & $90.7 \pm 23.4$ & $102.5 \pm 17.3[\mathrm{~B}]$ & $104.9 \pm 21.7[B]$ & $84.6 \pm 18.6[\mathrm{~A}]$ & $72.3 \pm 25.2[\mathrm{~A}]$ & $<0.0001$ \\
\hline FIV (I) & $2.7 \pm 1$ & $3.5 \pm 1[\mathrm{~B}]$ & $3.3 \pm 1[\mathrm{~B}]$ & $2.2 \pm 0.7[\mathrm{~A}]$ & $2.1 \pm 1[\mathrm{~A}]$ & $<0.0001$ \\
\hline FIF max (l/sec) & $4 \pm 1.6$ & $4.6 \pm 1.3[\mathrm{BC}]$ & $4.8 \pm 1.8[\mathrm{C}]$ & $3.7 \pm 1.4[\mathrm{AB}]$ & $2.7 \pm 1.2[\mathrm{~A}]$ & $<0.0001$ \\
\hline FIF max (\% pred) & $69.9 \pm 23.4$ & $78.2 \pm 22.9[\mathrm{~B}]$ & $79 \pm 25.2[\mathrm{~B}]$ & $66 \pm 21.8[\mathrm{AB}]$ & $56.6 \pm 13.8[\mathrm{~A}]$ & 0.0034 \\
\hline $\mathrm{MEF}_{25}(\mathrm{l} / \mathrm{sec})$ & $1.3 \pm 0.8$ & $2 \pm 0.7[\mathrm{~A}]$ & $1.5 \pm 0.8[\mathrm{~A}]$ & $0.9 \pm 0.7$ & $1.6 \pm 0.7[\mathrm{~A}]$ & $<0.0001$ \\
\hline $\mathrm{MEF}_{25} \%$ (\% pred) & $85.8 \pm 40.5$ & $120.9 \pm 33.3[\mathrm{C}]$ & $80.3 \pm 33.3[\mathrm{AB}]$ & $69.5 \pm 38[\mathrm{~A}]$ & $107.6 \pm 32.9[\mathrm{BC}]$ & $<0.0001$ \\
\hline TLC (L) & $5.3 \pm 1.2$ & $6.1 \pm 1.2[\mathrm{~B}]$ & $5.5 \pm 0.9[\mathrm{AB}]$ & $5.3 \pm 1[\mathrm{~A}]$ & $4.3 \pm 1$ & $<0.0001$ \\
\hline TLC (\% pred) & $90.2 \pm 16.6$ & $95.3 \pm 12[\mathrm{~A}]$ & $95.2 \pm 14.8[\mathrm{~A}]$ & $90.3 \pm 14.4[\mathrm{~A}]$ & $75.3 \pm 20.5$ & 0.0003 \\
\hline $\mathrm{RV}(\mathrm{L})$ & $2 \pm 0.7$ & $1.7 \pm 0.6[\mathrm{~A}]$ & $1.8 \pm 0.7[\mathrm{~A}]$ & $2.3 \pm 0.6$ & $1.8 \pm 0.7[\mathrm{~A}]$ & 0.0007 \\
\hline RV (\% pred) & $93.6 \pm 32.7$ & $82.8 \pm 23.3[\mathrm{AB}]$ & $91.6 \pm 33.1[\mathrm{AB}]$ & $104.5 \pm 30.5[\mathrm{~B}]$ & $79.4 \pm 36.1[\mathrm{~A}]$ & 0.0143 \\
\hline $\mathrm{I}_{\text {Raw }}(\mathrm{L})$ & $2.5 \pm 2.2$ & $1.5 \pm 1.4[\mathrm{~A}]$ & $3 \pm 2.9[\mathrm{~A}]$ & $2.7 \pm 1.8[\mathrm{~A}]$ & $2.4 \pm 1.3[\mathrm{~A}]$ & 0.0983 \\
\hline $\mathrm{E}_{\text {Raw }}(\mathrm{L})$ & $3.2 \pm 2.6$ & $1.8 \pm 0.8[\mathrm{~A}]$ & $2.9 \pm 2.6[\mathrm{AB}]$ & $4.3 \pm 2.9[\mathrm{~B}]$ & $3.1 \pm 2.2[\mathrm{AB}]$ & 0.0055 \\
\hline
\end{tabular}

Values sharing a letter in square brackets are not significantly different at the 5\% level (Tukey correction for multiple comparison). 
Table 2 also reports the results of multivariate logistic regression carried out in order to check any relationship between the inspiratory flow rate achieved in each group of subjects and other possible independent predictors. In general terms, $\mathrm{FEV}_{1}$ (both in absolute and in \% predicted values) did not contribute to predict the inspiratory airflow rate in whatever group of patients (Table 2). The lung function independent predictor uniquely assessed in the group of asthma patients was RV \% predicted (OR $=1.008,95 \% \mathrm{CI}$ 1.00 to 1.02 ). In COPD patients, the probability of achieving the expected inspiratory airflow rate decreased by increasing both RV in $\mathrm{L}(\mathrm{OR}=0.587,95 \% \mathrm{CI} 0.43$ to 0.8$)$ and $\mathrm{I}_{\text {Raw }}(\mathrm{OR}=0.901,95 \% \mathrm{CI}$ 0.8 to 1.01$)$. Finally, higher the FIF $\%$ predicted $(\mathrm{OR}=1.041,95 \%$ CI 0.99 to 1.1$)$ and lower the TLC \% predicted $(\mathrm{OR}=0.962,95 \%$ CI 0.94 to 0.99 ) values higher was the probability of achieving the expected inspiratory airflow rate in the restrictive sample of patients (Table 2).

The frequency of subjects who reached their inspiratory airflow rate expected value at the three different intrinsic resistance regimens in the four groups is reported in Figure 2.

\section{Discussion}

It is well accepted that DPIs represent a substantial improvement in inhalation delivery of respiratory drugs as they do not need propellants; simplify the inhalation procedures; improve the patient's adherence to treatment; minimize the variability of the

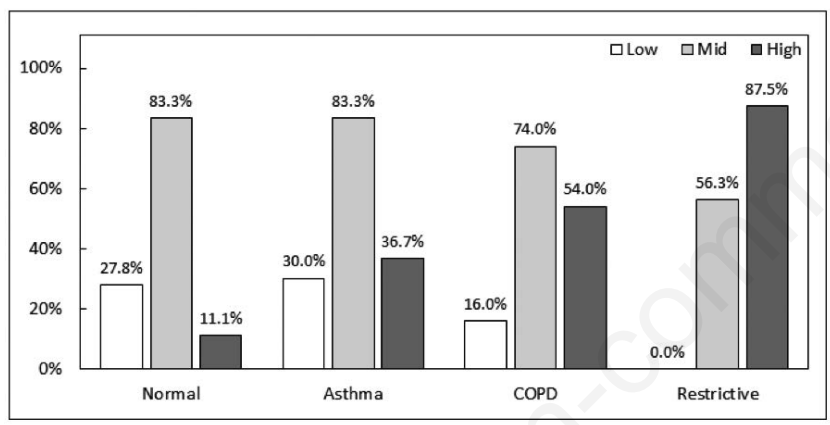

Figure 2. The frequency of subjects who reached their expected value of inspiratory airflow rate at the three different intrinsic resistance regimens in the four groups. dose to inhale; favour a higher deposition of drugs within the lungs; reduce the occurrence of local and systemic side effects, finally leading to better therapeutic outcomes $[4,21,22]$.

Though DPIs are widely and increasingly prescribed in clinical practice, the choice of the most convenient DPI to prefer still is a critical challenge in real-life [23] because available DPIs provide a wide range of inhalation and deposition patterns due to different physical, physiological and technological differences [3,24,25]. The relative role of these factors has been extensively investigated, even if evidence on optimal flow rates still largely derive from experimental or in vitro delivery data that only partially reproduce real-life clinical conditions [26-28].

Both the de-aggregation and the aerosolisation of dry powders to inhale may be related to the pressure drop produced during the inspiratory maneuver and to the subsequent flow rate (and/or the flow acceleration) through the device [9,29-33]. DPIs can then be characterized by their peculiar technological elements that allow variable degrees of airflow resistance, pressure drop/flow rates, and turbulence generated inside the device $[3,11,35]$. Even if the interactions occurring among pressure drops, flow rates, volumes, and DPI engineering represent a very complex issue indeed and their effects are difficult to generalize, it has been accepted that larger pressure drops, higher flow rates, and adequate inhaled volumes through any DPI device generally consent more effective powder dispersion, particle aerosolization, and larger drug amount reaching the lungs $[27,35,36]$. In particular, DPIs presently available can be ranked by their intrinsic resistance regimen in lowresistance ( $<5$ Mbar $0.51 / \mathrm{min}^{-1}$, Brezhaler); mid-resistance (5-10 Mbar 1/2 1/ $\mathrm{min}^{-1}$; Accuhaler, Diskhaler, Ellipta, Genuair; Spiromax, Clickhaler, Turbohaler, Easyhaler, Twisthaler, Nexthaler), and high-resistance devices (>10 Mbar 1/2 1/ $\mathrm{min}^{-1}$; Handihaler) $[11,34]$. Some critical aspects are still debated from this point of view. Inspiratory pressures needed are presumed to limit the patient's ability to generate a sufficient flow allowing the effective DPI use, even if it was also found a large variability of inhalation patterns, particularly when using low resistance devices [37]. Furthermore, patient's age and gender were described as the only variables affecting inspiratory flows through DPIs in some studies $[3,19,20]$, but not in other ones [36,38]. About this, to note that the real-life role of age and gender proved negligible also in the present study, and results of comparisons were independent of the resistive regimen tested.

In previous studies, the role of the original respiratory disease was described as marginal from this point of view, though it is known since long ago that different respiratory diseases can pecu-

Table 2. Lung function predictors of the expected inspiratory airflow rate assessed by multivariate logistic regression (after stepwise selection).

RV (\% pred.) $\quad 1.008$ (1 to 1.02 )

$\mathrm{I}_{\text {Raw }}(\mathrm{L})$

0.901 (0.8 to 1.01$)$

\section{DPI resistance \\ Low us mid}

High us mid

$0.091(0.02$ to 0.39$)$

$0.124(0.03$ to 0.45$)$
$0.052(0.01$ to 0.18$)$

$0.216(0.06$ to 0.84$)$
NA

$7.228(0.92$ to 56.76$)$ 
liarly compromise airway and parenchymal structures (i.e., muscles, elastic structures, etc.), and then their mechanical performance [39]. To keep also in mind that the inspiratory airflow rate generated is the only active force operating in the system: it is aimed to producing the sufficient pressure drop, to eliciting the resistance-induced turbulence into the device, thus allowing the effective disaggregation, micro-dispersion (even if differently sized for each device), and delivery of the powdered drug to inhale $[1,9,31]$. However, even if data comparing inspiratory airflow rates of the marketed DPIs are limited, it was also stated that the airflow rate achievable though a DPI is proportional to the square root of the pressure drop produced, and the lung dose increases with increasing airflow rate $[31,40,41]$.

Though minimized in some previous studies, the aspects related to subjects' lung function should not be neglected in our opinion as different lung disorders are characterized by different pathogenetic determinants (i.e., bronchial asthma, rather than COPD, or lung restriction) that can consequently lead to variably effects on patients' inspiratory/expiratory performances. This point becomes quite substantial in clinical practice, such as when the proper use of inhalation devices (DPIs in particular) becomes a crucial goal.

Interactions between pressure drops, inhalation flow rates, and DPI intrinsic resistance was not as much widely investigated in different respiratory conditions, particularly in the aim to compare the specific role of lung function parameters as predictors of proper DPIS use in different lung disorders. On the contrary, even if of different clinical value, each of these parameters encloses a physiological message and can suggest the presence of respiratory limitations that could affect the subject's DPIs use peculiarly. For instance, assumptions only based on changes in $\mathrm{FEV}_{1}$ (such as the simplest to obtain and then the most used) [42-44] likely do not allow to predict the inhalation performances through different DPIs in different pathological respiratory conditions exhaustively, because characterized by a too low specificity from this point of view. On the other hand, applied lung physiology is a much more complex issue and it cannot and should not be limited to a single, simple-to-obtain parameter. Different respiratory functions should be carefully assessed by appropriate parameters which contribute to clarify and predict specific respiratory limitations in clinical terms. The same careful multi-parametrical assessment should as much contribute to check and predict the determinant of subject's variable performances with different DPIs by their intrinsic resistive characteristics. To note that results of the present study tend to emphasize that, even in the presence of normal cognition and manual dexterity, the extent of inspiratory airflow through DPIs at different intrinsic resistance proved affected by subjects' basic airway (i.e., obstructive patients) and parenchymal conditions (i.e., restrictive patients). In other words, the deep and strong inspiratory airflow needed for overcoming the intrinsic resistance of different DPIs, and, consequently, for assuring the effective delivery of the powdered respiratory $\operatorname{drug}(\mathrm{s})$ into the airways results variably influenced by patients' specific lung limitations and characterized by some specific lung function predictors.

Data of the present study are suggesting that DPIs characterized by an intrinsic mid-resistance regimen are able to consent the most convenient inspiratory airflow rate with high prevalence, particularly in obstructive patients (i.e., in both asthma and in COPD patients): such as in those who most frequently need a DPI therapeutic prescription in clinical practice. Actually, the great majority of these patients proved able to perform their expected inspiratory airflow rate only when inhaling through a mid-resistance device, independently of their age, sex, and BMI. Comparable real-life results were not achieved with low- and high- resistance devices, except in the case of restrictive patients where quite low airflow rates were required (Figure 2). In particular, some lung function parameters proved highly discriminating and specific from this point of view, and their use can then be suggested as predictors of DPIs' effectiveness in different respiratory conditions. According to lung physiology, to point out that FIF and TLC represent the main predictors of the expected airflow rate in restrictive patients as their parenchymal conditions usually do not allow a huge lung inspiratory capacity. On the other hand, RV and $\mathrm{I}_{\text {Raw }}$ prove the best predictors of the expected airflow in obstructive patients, such as in those subjects where the significant reduction in airway patency represents the main aspect of their basic disorder. The net effects of these limitations are clearly mirrored by the variable proportion of patients who performed their expected inhalation airflow rate in the three different groups of respiratory patients (Figure 2). It should also be emphasized that, despite their normal lung function, a not negligible proportion of normal controls prove unable to achieve their expected limit of inspiratory airflow rate required when inhaling through the low-resistance regimen, likely because too high. Even if these subjects do not need any respiratory drug to inhale, this result is of value in our opinion because also individuals with normal lung function would be treated with other drugs via the inhalation route in the next future (i.e., vaccines, insuline, heparine, antibiotics, mucoactives, etc.).

The present study has some limitations. Data derive from a monocentric study and real-life oriented. The study was mainly focused on obstructive patients as they are those who need a therapeutic DPI prescription in the majority of cases and those who mostly need the proper utilization of the device. Measurements of the different resistance regimens carried out by means of the InCheck DIAL G16 were assumed as corresponding to those of DPIs, and then translated. The study also has some points of strengths in our opinion. Measurements were carried out in the three main prevalent respiratory pathologies vs normal controls. The subjects' capability of reaching the expected inspiratory flow rate was assessed and compared separately between the groups. Lung function analytically assessed in asthma, COPD, restrictive patients, and in normal controls corresponded to the functional profile expected for their basic respiratory disease (or condition), thus supporting some of the inferences suggested. Moreover, the specific value of some predictors of the proper inspiratory airflow rate was investigated for the first time by means of a large battery of plethysmographic parameters, such as the same physiological approach available and used for analytical diagnostic purposes in respiratory specialistic real-life. Statistical models for comparisons were carefully chosen.

\section{Conclusions}

The true effectiveness of DPIs still is a critical challenge in real life. The engineering peculiarities of DPIs, and their intrinsic resistive regimen in particular, can affect the extent of the inhalation airflow rate, even if at variable extent. Patients' lung function further contributes to affect the airflow rate per sè, being the effects peculiar for each subjects' basic respiratory disorder. Only some lung function parameters (i.e., FIF; RV; $\mathrm{I}_{\text {Raw }}$; TLC, but not $\mathrm{FEV}_{1}$ ) can contribute significantly and peculiarly to the specific prediction of the expected inspiratory airflow rate through DPIs in different lung disorders. In order to optimize and personalize the DPI choice more effectively, it is then suggested that, further to some peculiar technological aspects to know, the patients' basic respiratory disorder should be properly investigated and their current lung function carefully and analytically assessed. 


\section{References}

1. Virchow JC. Guidelines versus clinical practice - which therapy and which device. Respir Med 2004;98S28-34.

2. Virchow JC, Crompton GK, Dal Negro RW, Pedersen S, Magnan A, Seidemberg J, et al. Importance of inhaler devices in the management of airway diseases. Respir Med 2008;102:10-9.

3. Clark AR, Weers JG, Dhand R. The confusing world of dry powder inhalers: It is all about inspiratory pressures, not inspiratory flow rates. J Aerosol Med Pulm Drug Deliv 2020;33:1-11.

4. Wieshammer S, Dreyhaupt J. Dry powder inhalers: which factors determine the frequency of handling errors? Respiration 2008; $75: 18-25$.

5. Newman SP, Busse WW. Evolution of dry powder inhaler design, formulation, and performance. Respir Med 2002;96;293-304.

6. Chapman KR, Fogarty CM, Peckitt C, Lassen C, Jadayel D, Dedericha J, et al. Delivery characteristics and patients' handling of two single-dose dry powder inhalers used in COPD. Int J COPD 2011;6:353-6.

7. Sanchis J, Corrigan C, Levy M.L, Viejo JL. Inhaler devicesFrom theory to practice. Respir Med 2013;107:495-502.

8. Dal Negro RW, Turco P, Povero M. Patients' usability of seven most used dry-powder inhalers in COPD. Multidiscip Respir Med 2019;14:30.

9. Kruger P, Ehrlein, Zier M, Greguletz R. Inspiratory flow resistance of marketed dry powder inhalers. Eur Respir J 2014;44:abstract 4635.

10. Capstick TGD, Clifton IJ. Inhaler technique and training in people with chronic obstructive pulmonary disease and asthma. Exp Rev Respir Med 2012;6:91-103.

11. Sanders MJ. Guiding inspiratory flow: Development of the incheck DIAL G16, a tool for improving inhaler technique. Pulm Med 2017;2017:1495867.

12. Berkenfeld K, Lamprecht A, McConville JT. Devices for dry powder drug delivery to the lung, AAPS Pharm Sci Tech 2015;16:479-90.

13. Dederichs J, Singh D, Pavkov R. Inspiratory flow profiles generated by patients with COPD through the Breezhaler inhaler and other marketed dry powder inhalers. Am J Respir Crit Care Med 2015;191:A5793.

14. Canonica GW, Arp J, Keegstra JR, Chrystyn H. Spiromax, a new dry powder inhaler: dose consistency under simulated real-world conditions. J Aerosol Med Pulm Drug Deliv 2015;28:309-19.

15. Yakubu SI, Assi KH, Chrystyn H. Aerodynamic dose emission characteristics of dry powder inhalers using an Andersen Cascade Impactor with a mixing inlet: The influence of flow and volume. Int J Pharm 2013;455:213-8.

16. Frijlink HW, De Boer AH. Dry powder inhalers for pulmonary drug delivery. Exp Op Drug Del 2004;1:67-86.

17. Lexmond AJ, Kruizinga TJ, Hagedoorn P, Rottier BL, Frijlink HW, De Boer AH. Effect of inhaler design variables on paediatric use of dry powder inhalers. PLoS One 2014;9:99304.

18. Concato J, Peduzzi P, Holford TR, Feinstein AR. The importance of event per variable (EPV) in proportional hazard analysis: I. Background, goals and general strategy. J Clin Epidemiol 1995;48:1495-501.

19. Clark AR. The role of inspiratory pressures in determining the flow rate through dry powder inhalers; a review. Curr Pharm Design 2015;21:3973-83.

20. Malmberg LP, Rytilä P, Happonen P, Haahtela T. Inspiratory flows through dry powder inhaler in chronic obstructive pulmonary disease: age and gender rather than severity matters.
Int J Chron Obstr Pulm Dis 2010;5:257-62.

21. Crompton GK. Problems patients have using pressurized aerosol inhalers. Eur J Resp Dis 1982;63:S101-4.

22. Brocklebank D, Ram F, Wright J, Barry P, Cates C, Davies L, et al. Comparison of effectiveness of inhaler devices in asthma and chronic obstructive airway disease: a systematic review of the literature. Health Technol Asses 2001;5:1-149.

23. Thomas M, Williams AE. Are outcomes the same with all dry powder inhalers? Int J Clin Pract Suppl 2005;149:33-5.

24. Gustafsson P, Taylor A, Zanen P, Chrysyn H. Can patients use all dry powder inhalers equally well? Int J Clin Pract Suppl 2005;149:13-8.

25. Suarez-Barcelo M, Micca JL, Clackum S, Ferguson GT. Chronic obstructive pulmonary disease in long-term care setting: current practices, challenges, and unmet needs. Curr Opin Pulm Med 2017;23:s1-28.

26. Ung KT, Rao N, Weers JG, Clark AR, Chan HK. In vitro assessment of dose delivery performance of dry powders for inhalation. Aerosol Sci Technol 2014;48:1099-110.

27. Ung KT, Chan HK. Effects of ramp-up of inspired airflow on in vitro aerosol dose delivery performance of certain dry powder inhalers. Eur J Pharm Sci 2016;84:46-54.

28. Mohammed H, Arp I, Chambers F, Copley M, Glaab V, Hammond M, et al. Investigation of dry powder inhaler (DPI) resistance and aerosol dispersion timing on emitted aerosol aerodynamic particle sizing by multistage cascade impactor when sampled volume is reduced from compendial value of 4 L. AAPS Pharm Sci Tech 2014;15:1126-37.

29. Haidl P, Heindl S, Siemon K, Bernacka M, Cloes RM. Inhalation device requirements for patients' inhalation maneuvers. Respir Med 2016;118:65-75.

30. Buttini F, Brambilla G, Copelli D, Sisti V, Balducci AG, Bettini $\mathrm{R}$, et al. Effect of flow rate on in vitro aerodynamic performance of Nexthaler in comparison with Diskus and Turbohaler dry powder inhalers. J Aerosol Med Pulm Drug Del 2016;29: 167-78.

31. Dal Negro RW. Dry powder inhalers and the right things to remember: a concept review. Multidiscip Respir Med 2015; 10:13.

32. Laube BL, Janssens HM, De Jongh FHC, Devadason SG, Dhand R, Diot P, et al. What the pulmonary specialist should know about the new inhalation therapies. Eur Respir J 2011;37:1308-31.

33. Pedersen S, Hansen OR, Fuglsang G. Influence of inspiratory flow rate upon the effect of a Turbuhaler. Arch Dis Child 1990;65:308-10.

34. Berkenfeld K, Lamprecht A, McConville JT. Devices for dry powder drug delivery to the lung. AAPS Pharm Sci Tech 2015;16:479-90.

35. Weers J, Clark A. The impact of inspiratory flow rate on drug delivery to the lungs with dry powder inhalers. Pharm Res 2017;34:507-28.

36. Azouz W, Chetcuti P, Hosker H.S, Saralaya D, Stephenson J, Chrystyn H. The inhalation characteristics of patients when they use different dry powder inhalers. J Aerosol Med Pulm Drug Deliv 2015;28:35-42.

37. Altman P, Wehbe L, Dederichs J, Guerin T, Ament B, Cardenas Moronta $\mathrm{M}$, et al. Comparison of peak inspiratory flow rate via the Breezhaler ${ }^{\circledR}$, Ellipta ${ }^{\circledR}$ and HandiHaler ${ }^{\circledR}$ dry powder inhalers in patients with moderate to very severe COPD: a randomized cross-over trial. BMC Pulm Med 2018;18:100.

38. Laube BL, Janssens HM, de Jongh FH, Devadason SG, Dhand R, Diot $\mathrm{P}$, et al. What the pulmonary specialist should know about the new inhalation therapies. Eur Respir J 2011;37:1308-31.

39. Cook CD, Mead J, Orzalesi MM. Static volume/pressure char- 
acteristics of the respiratory system during maximal efforts. J Appl Physio. 1964;19:1016-22.

40. Clark AR, Hollingworth AM. The relationship between powder inhaler resistance and peak inspiratory conditions in healthy volunteers - Implications for in vitro testing. J Aerosol Med 1993;6:99-110.

41. Chapman KR, Fogarty CM, Peckitt C, Lassen C, Jadayel D, Dederichs J, et al. Delivery characteristics and patients' handling of two single-dose dry-powder inhalers used in COPD. Int J Chron Obstruct Pulmon Dis 2011;6:353-63.

42. Mahler DA, Waterman LA, Gifford AH. Prevalence and
COPD phenotype for a suboptimal peak inspiratory flow rate against the simulated resistance of the Diskus. J Aerosol Med Pulm Drug Deliv 2013;26:174-9.

43. Mahler DA, Waterman LA, Ward J, Gifford AH. Comparison of dry powder versus nebulized beta-agonist in patients with COPD who have suboptimal peak inspiratory flow rate. J Aerosol Med Pulm Drug Deliv 2014;27:103-9.

44. Janssens W, VandenBrande P, Hardeman E, De Langhe E, Philips T, Troosters T, et al. Inspiratory flow rates at different levels of resistance in elderly COPD patients. Eur Respir J 2008;31:78-83.

Received for publication: 8 February 2021. Accepted for publication: 24 March 2021.

This work is licensed under a Creative Commons Attribution-NonCommercial 4.0 International License (CC BY-NC 4.0).

(C) Copyright: the Author(s), 2021

Licensee PAGEPress, Italy

Multidisciplinary Respiratory Medicine 2021; $16: 752$

doi:10.4081/mrm.2021.752 